\title{
Seasonal Variations in the Daily Mortality Associated with Exposure to Particles, Nitrogen Dioxide, and Ozone in Stockholm, Sweden, from 2000 to 2016
}

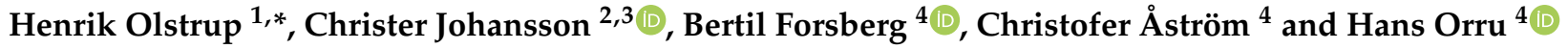 \\ 1 Institute of Family Medicine and Public Health, Faculty of Medicine, University of Tartu, Ravila 19, \\ 50411 Tartu, Estonia \\ 2 Atmospheric Science Unit, Department of Environmental Science, Stockholm University, \\ 11418 Stockholm, Sweden; christer.johansson@aces.su.se \\ 3 Environment and Health Administration, SLB-analys, Box 8136, 10420 Stockholm, Sweden \\ 4 Section of Sustainable Health, Department of Public Health and Clinical Medicine, Faculty of Medicine, \\ Umeå University, 90187 Umeå, Sweden; bertil.forsberg@umu.se (B.F.); christofer.astrom@umu.se (C.Å.); \\ Hans.Orru@ut.ee (H.O.) \\ * Correspondence: henrik.olstrup@ownit.nu; Tel.: +46-70-614-33-66
}

\section{check for} updates

Citation: Olstrup, H.; Johansson, C.; Forsberg, B.; Åström, C.; Orru, H. Seasonal Variations in the Daily Mortality Associated with Exposure to Particles, Nitrogen Dioxide, and Ozone in Stockholm, Sweden, from 2000 to 2016. Atmosphere 2021, 12, 1481. https://doi.org/10.3390/ atmos12111481

Academic Editors: Regina Duarte and Armando da Costa Duarte

Received: 14 October 2021

Accepted: 5 November 2021

Published: 9 November 2021

Publisher's Note: MDPI stays neutral with regard to jurisdictional claims in published maps and institutional affiliations.

Copyright: (c) 2021 by the authors. Licensee MDPI, Basel, Switzerland. This article is an open access article distributed under the terms and conditions of the Creative Commons Attribution (CC BY) license (https:/ / creativecommons.org/licenses/by/ $4.0 /)$.

\begin{abstract}
Urban air pollutant emissions and concentrations vary throughout the year due to various factors, e.g., meteorological conditions and human activities. In this study, seasonal variations in daily mortality associated with increases in the concentrations of $\mathrm{PM}_{10}$ (particulate matter), $\mathrm{PM}_{2.5-10}$ (coarse particles), $\mathrm{BC}$ (black carbon), $\mathrm{NO}_{2}$ (nitrogen dioxide), and $\mathrm{O}_{3}$ (ozone) were calculated for Stockholm during the period from 2000 to 2016. The excess risks in daily mortality are presented in single and multi-pollutant models during the whole year and divided into four different seasons, i.e., winter (December-February), spring (March-May), summer (June-August), and autumn (SeptemberNovember). The excess risks in the single-pollutant models associated with an interquartile range (IQR) increase for a lag 02 during the whole year were $0.8 \%(95 \% \mathrm{CI}: 0.1-1.4)$ for $\mathrm{PM}_{10}, 1.1 \%$ (95\% CI: 0.4-1.8) for $\mathrm{PM}_{2.5-10}$, 0.5\% (95\% CI: - 0.5-1.5) for BC, - 1.5\% (95\% CI: - 0.5--2.5) for $\mathrm{NO}_{2}$, and $1.9 \%$ (95\% CI: 1.0-2.9) for $\mathrm{O}_{3}$. When divided into different seasons, the excess risks for $\mathrm{PM}_{10}$ and $\mathrm{PM}_{2.5-10}$ showed a clear pattern, with the strongest associations during spring and autumn, but with weaker associations during summer and winter, indicating increased risks associated with road dust particles during these seasons. For BC, which represents combustion-generated particles, the pattern was not very clear, but the strongest positive excess risks were found during autumn. The excess risks for $\mathrm{NO}_{2}$ were negative during all seasons, and in several cases even statistically significantly negative, indicating that $\mathrm{NO}_{2}$ in itself was not harmful at the concentrations prevailing during the measurement period (mean values $<20 \mu \mathrm{g} \mathrm{m}^{-3}$ ). For $\mathrm{O}_{3}$, the excess risks were statistically significantly positive during "all year" in both the single and the multi-pollutant models. The excess risks for $\mathrm{O}_{3}$ in the single-pollutant models were also statistically significantly positive during all seasons.
\end{abstract}

Keywords: $\mathrm{PM}_{10} ; \mathrm{PM}_{2.5-10} ; \mathrm{BC} ; \mathrm{NO}_{2} ; \mathrm{O}_{3}$; excess health risks; multi-pollutant models; seasons

\section{Introduction}

While air pollutant emissions occur throughout the whole year, differences in meteorological conditions and human activities cause large seasonal variations in most pollutants. Kukkonen et al. (2000) [1] showed that meteorological variables in northern Europe vary widely with the seasons and, consequently, those variations are reflected in urban air quality. Apart from anthropogenic and natural emissions, among the main factors influencing seasonal variations in air quality are occurrence of temperature inversions, wind speed, precipitation, and solar radiation [2]. Particularly in the Nordic countries, where studded winter tires are used, suspension of coarse particles from road surfaces is highly dependent 
on surface moisture, which shows very large variations during the year, and with a major impact on the seasonal variations in the concentrations of both $\mathrm{PM}_{10}$ and $\mathrm{PM}_{2.5}$ [3].

The seasonal variations in air quality give rise to differences in health effects. In a study from the Netherlands, the associations between daily mortality and short-term variations in a number of air pollutants were analyzed during the period from 1986 to 1994, and the results were, among other things, divided into summer and winter seasons [4]. They found significantly $(95 \% \mathrm{CI})$ increased relative risks for all pollutants $\left(\mathrm{PM}_{10}\right.$, BS (black smoke), $\mathrm{O}_{3}, \mathrm{SO}_{2}, \mathrm{NO}_{2}, \mathrm{CO}, \mathrm{SO}_{4}{ }^{-2}$, and $\mathrm{NO}_{3}{ }^{-}$) during both summer and winter, except for $\mathrm{O}_{3}$ and $\mathrm{SO}_{4}{ }^{-2}$ during the winter. Moreover, the relative risks for total mortality associated with exposure to these air pollutants were in all cases larger during the summer compared to the winter [4].

Seasonal variations regarding short-term health effects associated with exposure to $\mathrm{PM}_{10}$ have been analyzed in a number of studies. When increased mortality associated with an increase in $\mathrm{PM}_{10}$ was analyzed in 100 cities in the U.S. in the period from 1987 to 2000, a significant association was found for the summer period, but no significant associations were found for the other three seasons. The seasonal pattern was also more pronounced in the northeast region of the U.S., while there were relatively small seasonal variations in the southern regions [5]. In Flanders, Belgium, where daily mortality associated with $\mathrm{PM}_{10}$ was calculated during the period from 1997 to 2003, and where temperature and seasons were included as potential effect modifiers, the strongest associations were also found during the summer [6]. Similarly, a significate effect of $\mathrm{PM}_{10}$ on mortality increase during the summer was found in Tallinn, Estonia, during the period from 2004 to 2011 [7]; however, during the winter, a significant decrease in mortality associated with an increase in $\mathrm{PM}_{10}$ appeared. In a study from China, where the association between daily mortality and an increase in $\mathrm{PM}_{10}$ was analyzed in 17 Chinese cities during different seasons, significant associations were found for summer and winter, but not for spring and autumn [8]. In another study from Wuhan, China, conducted from 2001 to 2004, the strongest associations for $\mathrm{PM}_{10}$ were found during winter [9]. In a study from Korea, where the associations between $\mathrm{PM}_{10}$ concentrations and increases in mortality and hospital admissions were analyzed in Seoul from 2000 to 2006, the effects on both mortality and morbidity increased during the summer [10]. Finally, in a study from Utah, U.S., the association between daily mortality and exposure to $\mathrm{PM}_{10}$ was examined for the period 1985 to 1992. The largest contribution to excess mortality was for individuals $75+$ years old dying in a hospital, and the strongest effect was shown during the spring [11].

Seasonal variations regarding short-term effects on hospitalization for cardiovascular diseases associated with $\mathrm{PM}_{2.5}$ were analyzed in New York State during the period 1991 to 2006. The strongest effects, associated with a $10 \mu \mathrm{g} \mathrm{m}{ }^{-3}$ increase in $\mathrm{PM}_{2.5}$, were found during the winter. Temperature modified the $\mathrm{PM}_{2.5}$ effects on cardiovascular diseases, and these effects were found on low temperature days [12]. In a study in Tallinn, $\mathrm{PM}_{2.5}$ increased mortality during the summer, but no effects appeared during the winter [7].

For particles in the coarse fraction $\left(\mathrm{PM}_{2.5-10}\right)$, the difference in short-term effects on daily mortality between two annual periods was analyzed in Stockholm during the period from 2000 to 2008. The associations between $\mathrm{PM}_{2.5-10}$ and daily mortality were stronger during November to May in comparison with the rest of the year, which can be explained by the high levels of road dust that occurs because of the use of studded tires in Stockholm during this time of the year [13].

The seasonal variations in short-term effects associated with $\mathrm{NO}_{2}$ were analyzed in a study from China. The daily mortality associated with $\mathrm{NO}_{2}$ in the city of Shenzhen in southeastern China during the period from 2013 to 2017 was analyzed during the cold season (November-April) and during the warm season (May-October). Significant excess risks for cardiovascular mortality associated with an increase in $\mathrm{NO}_{2}$ were found during the cold season at a 2-day lag and at a 6-day lag. However, no significant excess risks were found during the warm season [14]. 
The short-term health effects associated with $\mathrm{O}_{3}$ and their seasonal variations have been studied in U.S., France, and China. When the short-term mortality effects associated with $\mathrm{O}_{3}$ were analyzed in 20 communities in U.S., and where ten communities represented the northern part and ten represented the southern part, the seasonal variations in the effects estimates exhibited different results in the northern and southern parts. In the southern communities, an increase in $\mathrm{O}_{3}$ entailed increases in mortality during autumn and winter, while there were negative excess risks during spring and summer. In the northern communities, an increase in mortality was found during spring, summer and autumn, while there was a negative excess risk during the winter. In this study, latitude and seasonal average temperature were identified as effect modifiers [15]. In a study in nine French urban areas during the period from 1998 to 2006, the association between daily mortality and the daily max- $8 \mathrm{~h} \mathrm{O}_{3}$ concentrations was analyzed by season and by temperature strata. The strongest mortality effects were found during the summer and for the highest temperature strata [16]. In a study from China, the association between $\mathrm{O}_{3}$ and daily mortality was analyzed in the city of Zhengzhou during the period from 2013 to 2015. Significant excess risks associated with an increase in $10 \mu \mathrm{g} \mathrm{m}^{-3}$ 24-h average $\mathrm{O}_{3}$ concentrations at a 1-day lag were found during the cold season, but not during the warm season [17].

Based on the relatively few studies referenced above, it seems like the strongest excess risks of mortality for $\mathrm{PM}_{10}$ (seven studies) and $\mathrm{PM}_{2.5}$ (only two studies) occur during the summer months. For $\mathrm{NO}_{2}$ and $\mathrm{O}_{3}$, no consistent results in terms of seasonal dependence of excess risks can be seen. However, there are very few studies: only one study for $\mathrm{NO}_{2}$, and only three studies for $\mathrm{O}_{3}$.

The purpose of the current study was to analyze the seasonal variations in the effect estimates of air pollution on mortality in Stockholm. In the earlier analyzes, only annual data were considered, but the seasonal variations were not taken into account [18]. A special focus was to analyze the causes of the negative excess risks associated with $\mathrm{NO}_{2}$, and whether the seasons and other pollutants had any effect on these associations. Seasonal differences during the year can potentially affect the results in several ways. People are more likely to stay outdoors and have windows opened during the warm seasons, which can affect the degree of exposure. Annual variations in meteorology and air pollution sources can also be of importance. In Stockholm, the chemical composition of $\mathrm{PM}_{10}$ and $\mathrm{PM}_{2.5-10}$ varies throughout the year with a significantly higher proportion of mechanically generated road dust particles during early spring [3]. Analyzing the associations between mortality and short-term exposure to the above-mentioned air pollutants during different seasons in Stockholm is, therefore, of great interest.

\section{Materials and Methods}

This study includes residents of Stockholm, with a population that increased from 0.8 to 0.9 million during the period from 2000 to 2016. Population data were obtained from the Swedish Central Bureau of Statistics. Cause of mortality data were obtained from the National Cause of Death Register. Natural cause of mortality is defined on the basis of the underlying cause of death, and these data include the daily number of deaths from non-external causes (ICD-10: A00-R99) occurring among the registered population.

Air pollution exposure was estimated from a central measuring station on the roof-top of a $20 \mathrm{~m}$ high building in the central part of Stockholm. The monitoring station was part of the city's regulatory air pollution control network, and equipped with reference (or equivalent) instruments for regulated pollutants according to the EU air quality directive. These air pollutants included $\mathrm{PM}_{10}$ (particles with an aerodynamic diameter smaller than or equal to $10 \mu \mathrm{m}$ ), $\mathrm{PM}_{2.5}$ (particles with an aerodynamic diameter smaller than or equal to $2.5 \mu \mathrm{m}$ ), $\mathrm{NO}_{2}$ (nitrogen dioxide), and $\mathrm{O}_{3}$ (ozone) (Table 1). The $\mathrm{O}_{3}$ measurements were based on daily maximum 8 -h mean values. In addition, the monitoring included measurements of unregulated black carbon $(\mathrm{BC})$, and particles in the coarse fraction $\left(\mathrm{PM}_{2.5-10}\right)$ estimated by subtracting $\mathrm{PM}_{2.5}$ from $\mathrm{PM}_{10}$. The period from 2000 to 2016 was divided into 
winter (December-February), spring (March-May), summer (June-August), and autumn (September-November) seasons.

Table 1. Measurement methods and instruments used to measure the pollutants.

\begin{tabular}{|c|c|c|}
\hline Pollutant & Method & Instrument \\
\hline $\mathrm{PM}_{10}$ & Gravimetric & $\begin{array}{l}\text { TEOM 1400A, Thermo Fisher } \\
\text { Scientific, Waltham, MA, USA }\end{array}$ \\
\hline $\mathrm{PM}_{2.5}$ & Gravimetric & $\begin{array}{l}\text { TEOM 1400A, Thermo Fisher } \\
\text { Scientific, Waltham, MA, USA }\end{array}$ \\
\hline $\mathrm{PM}_{2.5-10}$ & $\begin{array}{c}\text { Gravimetric } \\
\text { (Subtracting } \mathrm{PM}_{2.5} \text { from } \mathrm{PM}_{10} \text { ) }\end{array}$ & $\begin{array}{l}\text { TEOM 1400A, Thermo Fisher } \\
\text { Scientific, Waltham, MA, USA }\end{array}$ \\
\hline $\mathrm{BC}$ & Transmission of lightthrough a filter & $\begin{array}{c}\text { Aethalometers 8100, AE31, AE33, } \\
\text { Magee Scientific Corporation, } \\
\text { Berkeley, CA, USA }\end{array}$ \\
\hline $\mathrm{NO}_{2}$ & Chemiluminescence & $\begin{array}{c}\text { AC32M, Environnement S.A., } \\
\text { Poissy, France }\end{array}$ \\
\hline $\mathrm{O}_{3}$ & UV absorption & $\begin{array}{c}\text { O342M, Environnement S.A., } \\
\text { Poissy, France }\end{array}$ \\
\hline
\end{tabular}

Temperature data were collected from the urban meteorological station Observatorielunden. In this study, daily maximum temperature was used as exposure variable.

The associations between different air pollutants and daily mortality were modelled using a quasi-Poisson regression model with a logistic link function. The concept "quasiPoisson" refers to a model that adjusts for overdispersed data, and a logistic link function defines the relationship of the dependent variables to the mean of the Poisson distributed independent variables. The modeling procedure was replicated from a previous study [18] in order to ensure comparability of the results. The model estimated the effect of an interquartile range (IQR) increase in air pollutants on daily mortality for lag 02 (average concentration during the same and the previous two days). The IQR values were calculated based on data for the whole year. Adjustments for other time-varying factors were made by assuming a linear additive effect on a logarithmic scale:

$$
\log \left(\mathrm{Yi}_{\mathrm{i}}=\text { Intercept }+\mathrm{AP}_{\mathrm{i}}+\mathrm{W}_{\mathrm{i}}+\mathrm{DOW}_{\mathrm{i}}+\right.\text { long-term trend }
$$

where $\mathrm{Yi}$ represents the daily number of deaths from non-external causes, $\mathrm{AP}_{\mathrm{i}}$ represents the concentration of a specific or a combination of air pollutants on day $\mathrm{i}, \mathrm{W}_{\mathrm{i}}$ represents variables controlling for the weather on day $i$ using smooth spline functions for the maximum temperature and snowfall, $\mathrm{DOW}_{\mathrm{i}}$ represents the day of the week, and the long-time trend is a smooth function varying over time to capture any long-term and seasonal patterns in mortality. The effects of air pollution were estimated by using a seasonal factor resulting in individual dose-responses for each season while keeping the other variable estimates constant for the whole period. Snowfall was included since it is a risk factor for daily mortality, as described in Auger et al. (2017) [19]. The smooth function describing the long-term time trend was a penalized regression spline restricted to 5 d.f. (degrees of freedom) per year. All pollutants were modelled by assuming a linear relationship with daily mortality. Air pollutants were first modelled in single-pollutant models, and trafficrelated pollutants were included in multi-pollutant models together with $\mathrm{O}_{3}$ and $\mathrm{PM}_{2.5-10}$. Temperature effects were adjusted by using two different smooth functions corresponding to the different lag-windows of $0-2$ and 3-10. The model allowed for the use of 4 d.f. for each function. All analyses were conducted using $\mathrm{R}$ statistical software version 3.6.0 ( $\mathrm{R}$ Foundation for Statistical Computing, Vienna, Austria). 


\section{Results}

\subsection{Descriptive Data}

In Table 2, summary statistics of the daily data regarding mortality, maximum temperature, and the measured air pollutants during the period from 2000 to 2016 are presented as mean values and IQR values for the whole year, and divided into four different seasons. $\mathrm{PM}_{10}, \mathrm{PM}_{2.5-10}$ and $\mathrm{O}_{3}$ show the highest concentrations during spring and the lowest during autumn/winter. For $\mathrm{NO}_{2}$ and $\mathrm{BC}$, the highest values are seen during winter and the lowest during summer. The seasonal variations reflect the different importance of emissions as discussed by Olstrup et al. (2019) [18].

Table 2. Summary statistics of the daily data from 2000 to 2016 during whole year and in four different seasons.

\begin{tabular}{cccccc}
\hline \multirow{2}{*}{ Variable } & Whole Year & Winter & Spring & Summer & Autumn \\
\cline { 2 - 6 } & & Mean (IQR) & \\
\hline Mortality (cases per day) & $18.5(7.0)$ & $20.2(6.0)$ & $18.7(6.0)$ & $17.0(6.0)$ & $17.9(6.0)$ \\
Maximum temperature $\left({ }^{\circ} \mathrm{C}\right)$ & $11.4(15.0)$ & $1.4(5.6)$ & $10.9(9.8)$ & $22.2(5.0)$ & $11.0(8.3)$ \\
$\mathrm{PM}_{10}\left(\mu \mathrm{g} \mathrm{m}^{-3}\right)$ & $14.5(8.7)$ & $12.2(7.7)$ & $20.5(13.7)$ & $12.9(5.9)$ & $12.2(6.7)$ \\
$\mathrm{PM}_{2.5-10}\left(\mu \mathrm{g} \mathrm{m}^{-3}\right)$ & $8.0(5.5)$ & $5.5(3.7)$ & $13.1(10.8)$ & $6.8(3.8)$ & $6.3(3.8)$ \\
$\left.\mathrm{BC}^{-3} \mathrm{~g} \mathrm{~m}^{-3}\right)$ & $0.6(0.5)$ & $0.7(0.6)$ & $0.6(0.4)$ & $0.5(0.5)$ & $0.7(0.5)$ \\
$\mathrm{NO}_{2}\left(\mu \mathrm{g} \mathrm{m}^{-3}\right)$ & $14.4(9.9)$ & $17.6(11.5)$ & $14.0(9.4)$ & $10.8(7.4)$ & $15.2(9.6)$ \\
$\mathrm{O}_{3}\left(\mu \mathrm{g} \mathrm{m}^{-3}\right)^{*}$ & $51.2(25.2)$ & $41.6(20.1)$ & $66.1(17.4)$ & $58.0(17.5)$ & $38.8(18.0)$ \\
\hline
\end{tabular}

${ }^{*} \mathrm{O}_{3}$ measurements were based on daily maximum 8-h mean values.

The number of days with valid data is presented for each variable in Table A1 in Appendix A. Pearson correlation coefficients between the different air pollutants during all year and divided into different seasons are presented in Tables A2-A6 in Appendix A.

\subsection{Calculated Excess Risks}

Figures 1-6 show the calculated excess risks for daily mortality associated with an IQR increase in the measured pollutants in Stockholm during the period from 2000 to 2016. The measured air pollutants are presented in Table 2. The figures are divided into different sections where the whole year is presented furthest to the left, and then from left to right winter (December-February), spring (March-May), summer (June-August), and autumn (September-November). Figure 1 presents a single-pollutant model, and Figures 2-6 present multi-pollutant models where adjustments for other pollutants have been made. The excess risks for daily mortality associated with exposure to the different air pollutants were based on lag02, which means a lagging effect of the air pollution exposure during the same and the previous two days.

The excess risks associated with exposure to $\mathrm{PM}_{10}$ and $\mathrm{PM}_{2.5-10}$ (Figures 2 and 3) showed a clear pattern with the strongest associations during spring and autumn, but with weaker associations during summer and winter. For BC (Figure 4), which represents combustion-generated particles, the pattern was not very clear, but the strongest positive excess risks were found during autumn. The excess risks associated with exposure to $\mathrm{NO}_{2}$, presented in Figure 5, were significantly (95\% CI) negative based on "all year", and especially strong negative associations were shown during the autumn after adjustments for $\mathrm{PM}_{2.5-10}$ and BC. For $\mathrm{O}_{3}$ (Figure 6), the excess risks were significantly (95\% CI) positive during "all year" in both the single and the multi-pollutant models. The single-pollutant models were also significantly positive during all seasons, and the highest excess risk appeared during the autumn. 


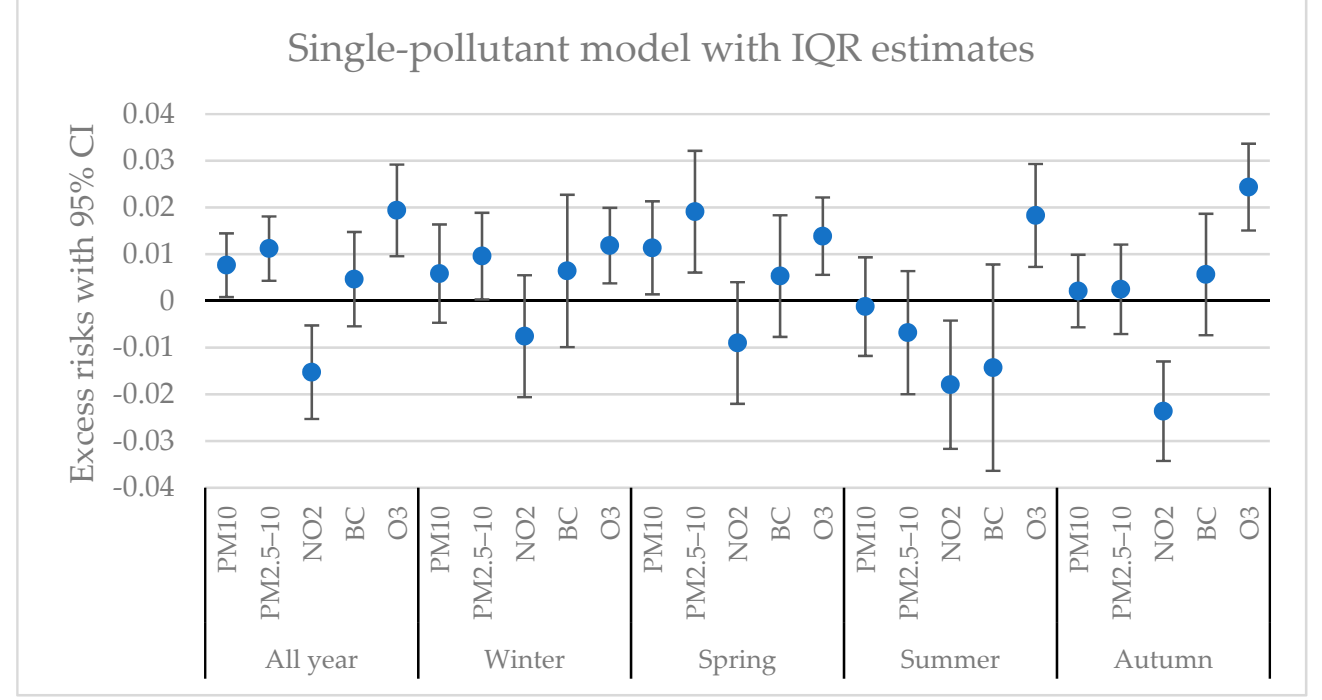

Figure 1. Estimated excess risks in daily mortality with $95 \% \mathrm{CI}$ (lag02) for an IQR increase in the concentrations of $\mathrm{PM}_{10}, \mathrm{PM}_{2.5-10}, \mathrm{NO}_{2}, \mathrm{BC}$ and $\mathrm{O}_{3}$ in single-pollutant models divided into all year and four different seasons.

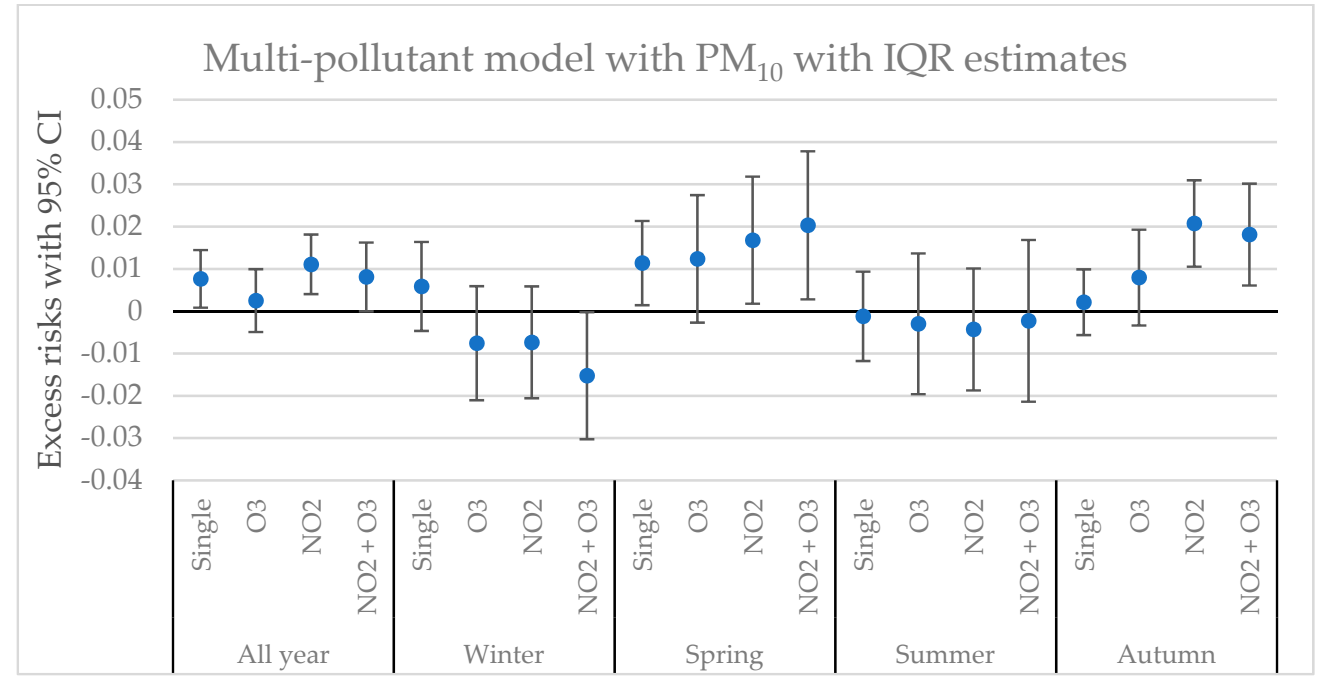

Figure 2. Estimated excess risks in daily mortality with 95\% CI (lag02) for an IQR increase in the concentrations of $\mathrm{PM}_{10}$. The calculations are divided into all year and four different seasons. The excess risks are presented as single-pollutant estimates and multi-pollutant estimates with $\mathrm{O}_{3}, \mathrm{NO}_{2}$ and $\mathrm{NO}_{2}+\mathrm{O}_{3}$ included in the calculations. 


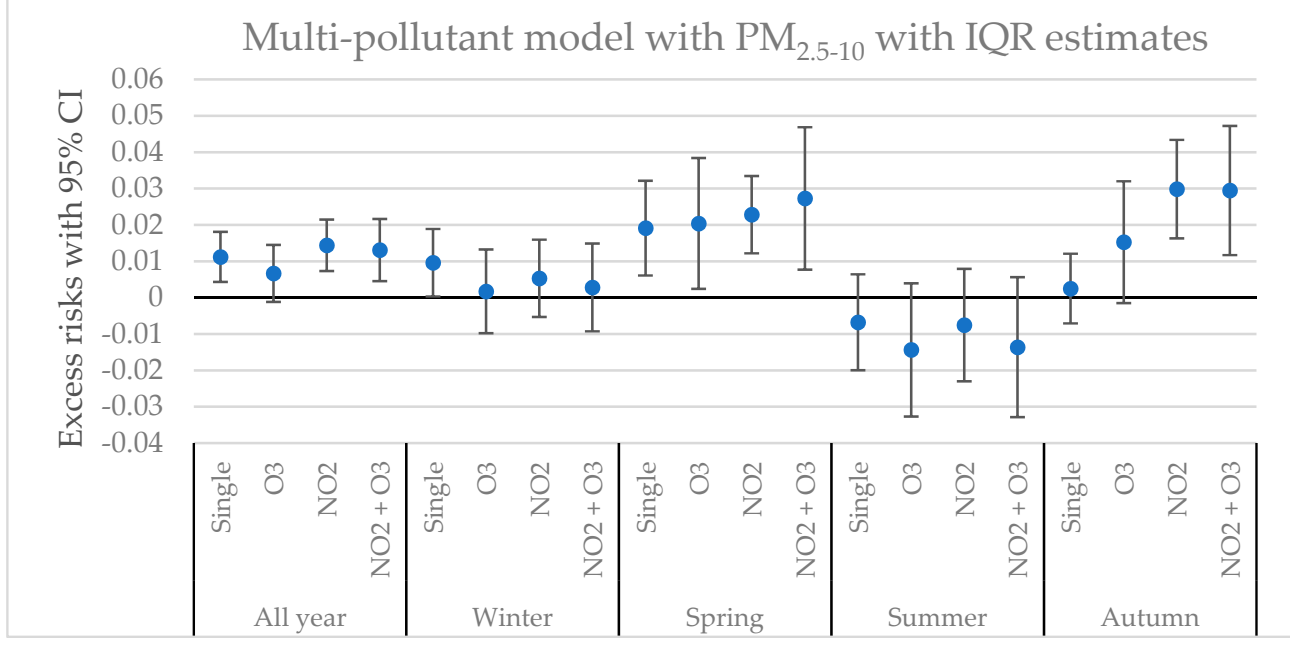

Figure 3. Estimated excess risks in daily mortality with 95\% CI (lag02) for an IQR increase in the concentrations of $\mathrm{PM}_{2.5-10}$. The calculations are divided into all year and four different seasons. The excess risks are presented as single-pollutant estimates and multi-pollutant estimates with $\mathrm{O}_{3}, \mathrm{NO}_{2}$ and $\mathrm{NO}_{2}+\mathrm{O}_{3}$ included in the calculations.

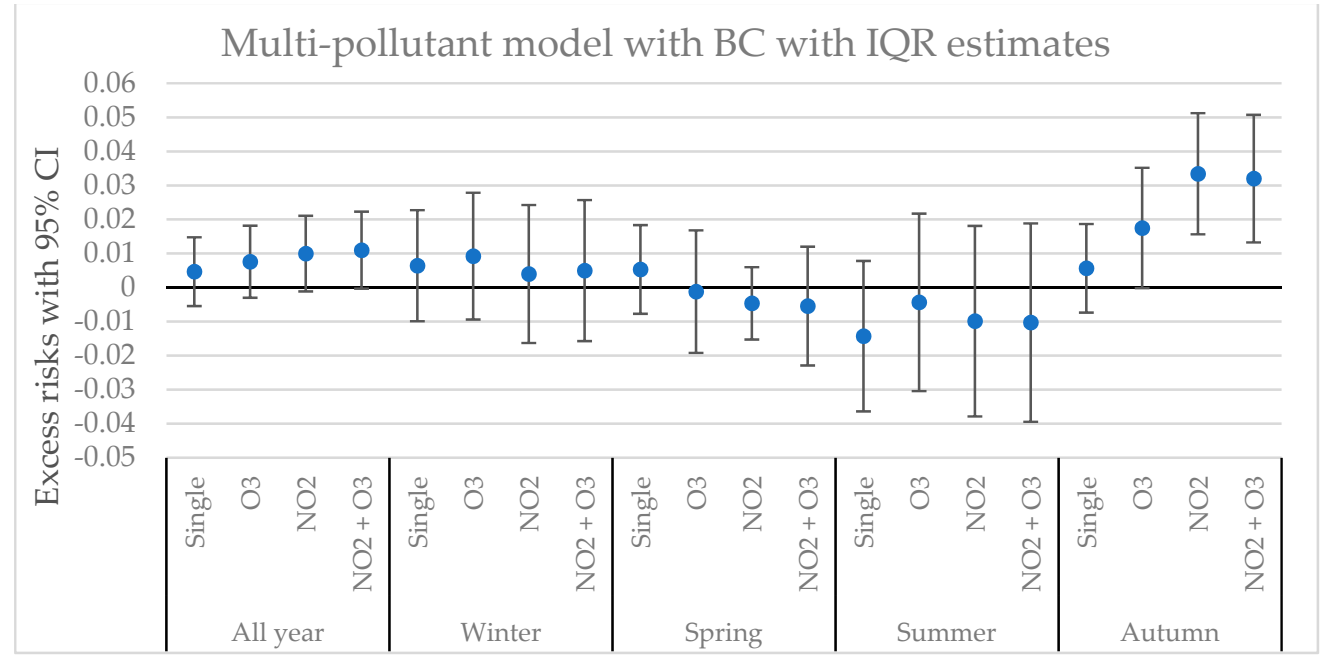

Figure 4. Estimated excess risks in daily mortality with 95\% CI (lag02) for an IQR increase in the concentrations of BC. The calculations are divided into all year and four different seasons. The excess risks are presented as single-pollutant estimates and multi-pollutant estimates with $\mathrm{O}_{3}, \mathrm{NO}_{2}$ and $\mathrm{NO}_{2}+\mathrm{O}_{3}$ included in the calculations. 


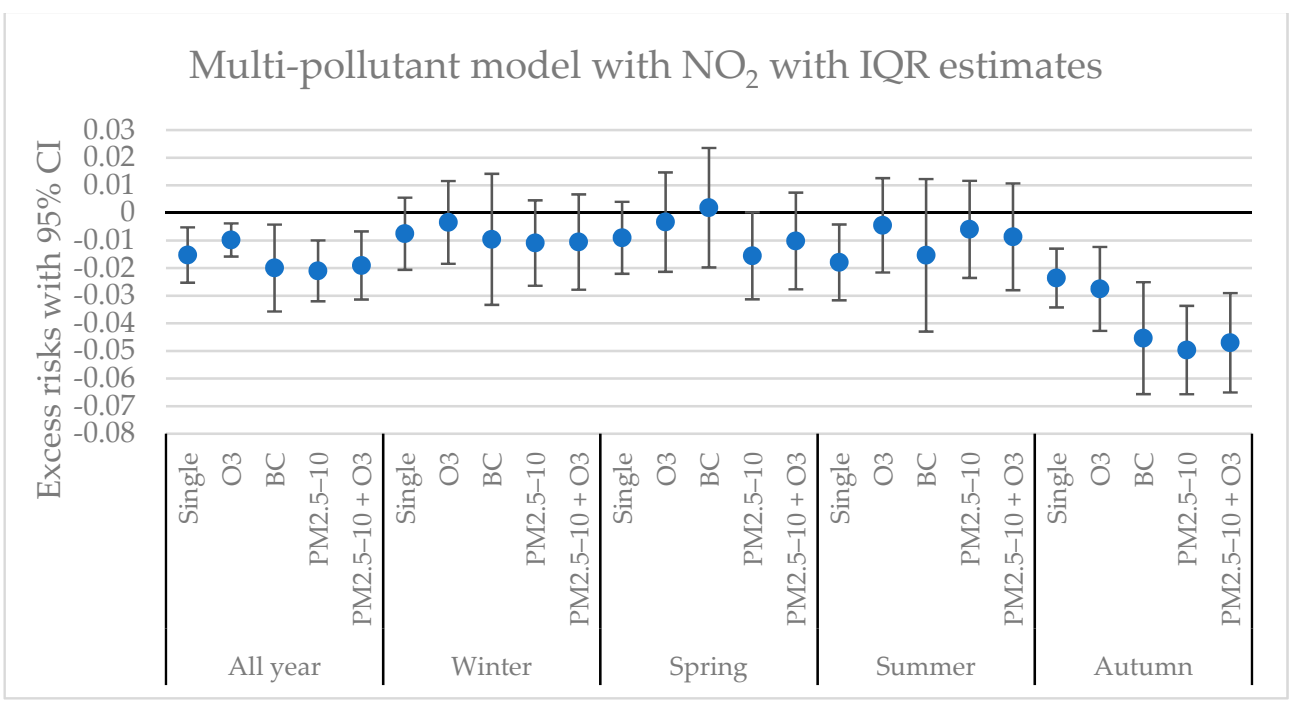

Figure 5. Estimated excess risks in daily mortality with 95\% CI (lag 02) for an IQR increase in the concentrations of $\mathrm{NO}_{2}$. The calculations are divided into all year and four different seasons. The excess risks are presented as single-pollutant estimates and multi-pollutant estimates with $\mathrm{O}_{3}, \mathrm{BC}$, $\mathrm{PM}_{2.5-10}$ and $\mathrm{PM}_{2.5-10}+\mathrm{O}_{3}$ included in the calculations.



Figure 6. Estimated change in daily mortality with 95\% CI (lag02) for an IQR increase in the concentrations of $\mathrm{O}_{3}$. The calculations are divided into all year and four different seasons. The excess risks are divided into single-pollutant estimates and multi-pollutant estimates with $\mathrm{PM}_{2.5-10}, \mathrm{NO}_{2}$ and $\mathrm{BC}$ included in the calculations.

\section{Discussion}

Calculated Excess Risks and Possible Explanations for Their Seasonal Variations

The main objective of this study was to analyze if the daily mortality associated with exposure to the different air pollutants were different when different seasons were analyzed separately, and if the results were significantly different compared to when the analyses were based on the whole year without regard to the seasons. An important issue was whether behavioral factors regarding the amount of outdoor stay, which varies depending on the season, could have affected the results.

The excess risks associated with $\mathrm{PM}_{2.5-10}$ and $\mathrm{PM}_{10}$ exhibited a broadly similar pattern with larger excess risks in daily mortality during springtime compared to the other seasons. The seasonal pattern of the excess risks for $\mathrm{PM}_{10}$ and $\mathrm{PM}_{2.5-10}$ can possibly be explained by 
the seasonal variation in the chemical composition throughout the year. During springtime, up to $90 \%$ of the mass of $\mathrm{PM}_{10}$ in Stockholm originates from road abrasion that occurs when the road surfaces become drier [3]. The large proportion of $\mathrm{PM}_{10}$ during springtime is road dust that is mainly represented in the coarse fraction $\left(\mathrm{PM}_{2.5-10}\right)$, and this is mainly caused by the use of studded tires during the winter months [20]. A large number of detrimental effects on the respiratory and the cardiovascular system linked to the components of road dust particles have been showed in a literature review from 2018 [21].

The excess risks associated with BC were statistically significant only in two out of the studied 20 cases. In terms of percentage of days with valid data, $\mathrm{BC}$ differed from the other pollutants by having a data coverage of just over $50 \%$ in comparison with $\mathrm{NO}_{2}, \mathrm{O}_{3}$, and $\mathrm{PM}_{10}$ with a data coverage of $96-100 \%$, and $\mathrm{PM}_{2.5-10}$ with a data coverage of $83-88 \%$ (Table A1, Appendix A). A relatively smaller amount of data might have made the excess risk estimates less accurate. However, the data coverage for $\mathrm{BC}$ was greater during the latter part of the measurement period. Additionally, in a previous study, where BC measurements were compared at different measuring sites in Stockholm, the spatiotemporal variability was not found to be very high, and different urban sites were poorly correlated even for daily averages $(R<0.70)[22]$. Consequently, this means that the use of measurement data for $\mathrm{BC}$ from one single measurement station may have led to exposure misclassification, leading to even greater uncertainties regarding the calculations of the excess risks.

The reasons for the negative excess risks associated with $\mathrm{NO}_{2}$ are not entirely clear. The hypothesis in the previous study [18] was that seasonal variations in exposure could be an explanation, and that the exposure was greater during the warm season. In that case, an expected result would be that the excess risks during the summer would be greater compared to the winter, but no indications of higher excess risks during the warm season could be seen. However, a lack of positive associations between daily mortality and exposure to $\mathrm{NO}_{2}$ has been shown for Stockholm in previous studies as well [23,24]. It may be possible that $\mathrm{NO}_{2}$ in itself, at these low concentrations, has no significant effects on short-term mortality, but that oxidants in the air might have a crucial importance.

The lack of positive excess risks associated with $\mathrm{NO}_{2}$ may also be due to concentrations that were below the threshold for adverse health effects. Experimental studies with humans demonstrated noticeable effects after short-term exposure to $\mathrm{NO}_{2}$ concentrations at or above $400 \mu \mathrm{g} \mathrm{m}^{-3}$, and health effects on patients with mild asthma could not be detected after short-term exposure to concentrations below $200 \mathrm{\mu g} \mathrm{m}^{-3}$ [25]. Based on a review of several studies on exposure to $\mathrm{NO}_{2}$, increased mortality was suggested above a threshold value of $20 \mu \mathrm{g} \mathrm{m}^{-3}$ [26]. The average $\mathrm{NO}_{2}$ concentrations in this study were below $20 \mu \mathrm{g} \mathrm{m}^{-3}$ during all seasons. An earlier analysis including older data with higher $\mathrm{NO}_{2}$ values (median concentration of $26.8 \mathrm{\mu g} \mathrm{m}^{-3}$ ) in Stockholm increased the mortality risk [27], whereas the current study with lower concentrations did not. However, in the former study, the control for temperature effects on daily mortality included only a short lag. In this study, the control for low temperature effects included a lag-window of 3-10 days. There is a possibility that the temperature adjustments capture some effects of exhaust gases. Another factor that could contribute to the lack of positive associations with daily mortality is exposure misclassification as discussed above in the case of BC.

Effect modifications by oxidants regarding the health effects associated with $\mathrm{PM}_{2.5}$ were shown in a multi-city case-crossover study in Canada where the relationships between $\mathrm{PM}_{2.5}$ and daily mortality were greater in connection with elevated oxidant gas concentrations [28]. The importance of reactive oxygen species (ROS) has also been addressed in a cohort study from Canada where the association between ROS in lung fluid and exposures to $\mathrm{PM}_{2.5}$ containing $\mathrm{Fe}$ and $\mathrm{Cu}$ were estimated using land use regression models. Longterm exposure to $\mathrm{Fe}$ and $\mathrm{Cu}$ in $\mathrm{PM}_{2.5}$ and their combined impact on ROS were consistently associated with increased cardiovascular mortality. Interestingly, adjustments for ROS did not significantly change the effects on cardiovascular diseases and mortality associated with exposure to $\mathrm{PM}_{2.5}$, but the effects associated with exposure to $\mathrm{NO}_{2}$ decreased significantly after adjustments for ROS, indicating the importance of non-exhaust particulate air 
pollution [29]. The results in this study, with a lack of positive excess risks associated with $\mathrm{NO}_{2}$, but with significantly positive excess risk for $\mathrm{PM}_{2.5-10}$ during spring time when there is a large amount of road dust, indicate that ROS could have been a contributing factor. However, in the current study, there was no information on ROS in Stockholm.

Among all the air pollutants that were analyzed in this study, the excess risks associated with $\mathrm{O}_{3}$ were the most robust in terms of health impact, with significantly positive excess risks in 12 out of the 20 cases. Based on the "all year" calculations, the excess risks associated with $\mathrm{O}_{3}$ were fairly similar in both the single and the multi-pollutant models. However, the results for the different seasons were inconclusive. However, relatively higher excess risks for $\mathrm{O}_{3}$ during summer and autumn compared to winter and spring were shown in the single-pollutant models. Higher excess risks for $\mathrm{O}_{3}$-related mortality during the warm season were also shown in Stockholm in a previous study by Bedada et al. (2016) [23]. Since there are few indoor sources of ozone, an increased exposure during the warmer season can at least partially explain the higher excess risks in the single-pollutant models during the warm seasons.

\section{Conclusions}

The main objective of this study was to analyze seasonal variations in the excess risks for daily mortality associated with an interquartile range increase in $\mathrm{PM}_{10}, \mathrm{PM}_{2.5-10}$, $\mathrm{BC}, \mathrm{NO}_{2}$, and $\mathrm{O}_{3}$ in Stockholm during the period from 2000 to 2016. Both single and multi-pollutant models were used in the analysis.

The current study showed a broadly similar pattern for excess risks associated with $\mathrm{PM}_{2.5-10}$ and $\mathrm{PM}_{10}$ with larger risk increases in daily mortality during springtime. The seasonal pattern of the excess risks for $\mathrm{PM}_{10}$ and $\mathrm{PM}_{2.5-10}$ can possibly be explained by the variation in the chemical composition throughout the year, with a larger amount of road dust present during springtime. The excess risks associated with BC were, in most cases, statistically insignificant, which may be due to the fact that the amount of data on which the calculations were based was smaller in comparison with the other air pollutants.

The calculated excess risks for $\mathrm{NO}_{2}$ were negative in almost all cases throughout the whole year. Differences in exposure during the year, which previously was hypothesized as an explanation for the negative excess risks, are unlikely. One possible reason for the negative excess risks associated with $\mathrm{NO}_{2}$ is that the concentrations (on average $14.4 \mu \mathrm{g}$ $\mathrm{m}^{-3}$ ) in this study were too low to cause harmful health effects.

The excess risks associated with $\mathrm{O}_{3}$ were most robust in terms of the number of statistically significantly positive relationships, indicating that $\mathrm{O}_{3}$ and its oxidative potential were particularly important in terms of daily mortality associated with air pollution exposure. Higher excess risks were shown during summer and autumn, indicating a higher degree of exposure during the warm seasons.

From a policy point of view, there were clear indications that the health effects associated with exposure to $\mathrm{PM}_{2.5-10}$ and $\mathrm{PM}_{10}$ were most evident during the spring. Additional action strategies to reduce the emissions of road dust particles are, therefore, needed.

Author Contributions: Conceptualization: H.O. (Henrik Olstrup) and B.F.; methodology: H.O. (Henrik Olstrup) and C.Å.; data analysis: H.O. (Henrik Olstrup), C.J., B.F., C.Å., and H.O. (Hans Orru); writing — original draft preparation: H.O. (Henrik Olstrup) and H.O. (Hans Orru); writingreview and editing: C.J., B.F., C.A. and H.O. (Hans Orru). All authors have read and agreed to the published version of the manuscript.

Funding: This research was partly financed by the Swedish Environmental Protection Agency.

Institutional Review Board Statement: Not applicable.

Informed Consent Statement: Not applicable.

Data Availability Statement: The data presented in this study are available on request from the corresponding author. 
Acknowledgments: The authors would like to thank four anonymous reviewers for review and improvement suggestions.

Conflicts of Interest: The authors declare no conflict of interest. The funders had no role in the design of the study; in the collection, analyses, or interpretation of data; in the writing of the manuscript, or in the decision to publish the results.

\section{Appendix A}

Table A1. Numbers and percentage of days with valid data for the measured variables during the period from 2000 to 2016 divided into whole year and four different seasons. Mortality is indicated as cases per day, maximum temperature in ${ }^{\circ} \mathrm{C}$, and air pollutants in $\mu \mathrm{g} \mathrm{m}^{-3}$.

\begin{tabular}{cccccc}
\hline \multirow{2}{*}{ Variable } & Whole Year & Winter & Spring & Summer & Autumn \\
\cline { 2 - 5 } & \multicolumn{5}{c}{ \#Days (\% Valid Data) } \\
\hline Mortality & $6210(100 \%)$ & $1535(100 \%)$ & $1564(100 \%)$ & $1564(100 \%)$ & $1548(100 \%)$ \\
Maximum & $6210(100 \%)$ & $1535(100 \%)$ & $1564(100 \%)$ & $1564(100 \%)$ & $1548(100 \%)$ \\
temperature & $5999(97 \%)$ & $1474(96 \%)$ & $1533(98 \%)$ & $1500(96 \%)$ & $1492(96 \%)$ \\
$\mathrm{PM}_{10}$ & $5352(86 \%)$ & $1298(85 \%)$ & $1378(88 \%)$ & $1356(87 \%)$ & $1277(83 \%)$ \\
$\mathrm{PM}_{2.5-10}$ & $3316(53 \%)$ & $764(50 \%)$ & $906(58 \%)$ & $791(51 \%)$ & $855(55 \%)$ \\
$\mathrm{BC}^{*}$ & $6101(98 \%)$ & $1504(98 \%)$ & $1533(98 \%)$ & $1527(98 \%)$ & $1537(99 \%)$ \\
$\mathrm{NO}_{2}$ & $6133(99 \%)$ & $1531(100 \%)$ & $1553(99 \%)$ & $1532(98 \%)$ & $1517(98 \%)$ \\
$\mathrm{O}_{3}$ & & & &
\end{tabular}

Table A2. Correlation matrix with R-values (Pearson correlation coefficients) between the different air pollutants measured in Stockholm during the whole year during the period from 2000 to 2016.

\begin{tabular}{cccccc}
\hline Pollutant & $\mathbf{P M}_{\mathbf{1 0}}$ & $\mathbf{P M}_{\mathbf{2 . 5}-\mathbf{1 0}}$ & $\mathbf{B C}$ & $\mathbf{N O}_{\mathbf{2}}$ & $\mathbf{O}_{\mathbf{3}}$ \\
\hline $\mathrm{PM}_{10}$ & 1 & 0.81 & 0.49 & 0.25 & 0.31 \\
$\mathrm{PM}_{2.5-10}$ & 0.81 & 1 & 0.13 & 0.12 & 0.35 \\
$\mathrm{BC}$ & 0.49 & 0.13 & 1 & 0.49 & -0.25 \\
$\mathrm{NO}_{2}$ & 0.25 & 0.12 & 0.49 & 1 & -0.46 \\
$\mathrm{O}_{3}$ & 0.31 & 0.35 & -0.25 & -0.46 & 1 \\
\hline
\end{tabular}

Table A3. Correlation matrix with R-values (Pearson correlation coefficients) between the different air pollutants measured in Stockholm during wintertime (December, January and February) during the period from 2000 to 2016.

\begin{tabular}{cccccc}
\hline Pollutant & $\mathbf{P M}_{\mathbf{1 0}}$ & $\mathbf{P M}_{\mathbf{2 . 5}-\mathbf{1 0}}$ & $\mathbf{B C}$ & $\mathbf{N O}_{\mathbf{2}}$ & $\mathbf{O}_{\mathbf{3}}$ \\
\hline $\mathrm{PM}_{10}$ & 1 & 0.67 & 0.56 & 0.24 & -0.02 \\
$\mathrm{PM}_{2.5-10}$ & 0.67 & 1 & 0.05 & 0.11 & 0.13 \\
$\mathrm{BC}$ & 0.56 & 0.05 & 1 & 0.48 & -0.45 \\
$\mathrm{NO}_{2}$ & 0.24 & 0.11 & 0.48 & 1 & -0.62 \\
$\mathrm{O}_{3}$ & -0.02 & 0.13 & -0.45 & -0.62 & 1 \\
\hline
\end{tabular}

Table A4. Correlation matrix with R-values (Pearson correlation coefficients) between the different air pollutants measured in Stockholm during springtime (March, April and May) during the period from 2000 to 2016.

\begin{tabular}{cccccc}
\hline Pollutant & $\mathbf{P M}_{\mathbf{1 0}}$ & $\mathbf{P M}_{\mathbf{2 . 5}-\mathbf{1 0}}$ & $\mathbf{B C}$ & $\mathbf{N O}_{\mathbf{2}}$ & $\mathbf{O}_{\mathbf{3}}$ \\
\hline $\mathrm{PM}_{10}$ & 1 & 0.83 & 0.66 & 0.46 & 0.18 \\
$\mathrm{PM}_{2.5-10}$ & 0.83 & 1 & 0.31 & 0.33 & 0.14 \\
$\mathrm{BC}$ & 0.66 & 0.31 & 1 & 0.54 & -0.06 \\
$\mathrm{NO}_{2}$ & 0.46 & 0.33 & 0.54 & 1 & -0.40 \\
$\mathrm{O}_{3}$ & 0.18 & 0.14 & -0.06 & -0.40 & 1 \\
\hline
\end{tabular}


Table A5. Correlation matrix with R-values (Pearson correlation coefficients) between the different air pollutants measured in Stockholm during summertime (June, July and August) during the period from 2000 to 2016.

\begin{tabular}{cccccc}
\hline Pollutant & $\mathbf{P M}_{\mathbf{1 0}}$ & $\mathbf{P M}_{\mathbf{2 . 5}-\mathbf{1 0}}$ & $\mathbf{B C}$ & $\mathbf{N O}_{\mathbf{2}}$ & $\mathbf{O}_{\mathbf{3}}$ \\
\hline $\mathrm{PM}_{10}$ & 1 & 0.71 & 0.55 & 0.40 & 0.44 \\
$\mathrm{PM}_{2.5-10}$ & 0.71 & 1 & 0.19 & 0.16 & 0.25 \\
$\mathrm{BC}$ & 0.55 & 0.19 & 1 & 0.55 & 0.11 \\
$\mathrm{NO}_{2}$ & 0.40 & 0.16 & 0.55 & 1 & -0.16 \\
$\mathrm{O}_{3}$ & 0.44 & 0.25 & 0.11 & -0.16 & 1 \\
\hline
\end{tabular}

Table A6. Correlation matrix with R-values (Pearson correlation coefficients) between the different air pollutants measured in Stockholm during autumn time (September, October and November) during the period from 2000 to 2016.

\begin{tabular}{cccccc}
\hline Pollutant & $\mathbf{P M}_{\mathbf{1 0}}$ & $\mathbf{P M}_{\mathbf{2 . 5}-\mathbf{1 0}}$ & $\mathbf{B C}$ & $\mathbf{N O}_{\mathbf{2}}$ & $\mathbf{O}_{\mathbf{3}}$ \\
\hline $\mathrm{PM}_{10}$ & 1 & 0.69 & 0.69 & 0.19 & 0.06 \\
$\mathrm{PM}_{2.5-10}$ & 0.69 & 1 & 0.32 & 0.14 & 0.12 \\
$\mathrm{BC}$ & 0.69 & 0.32 & 1 & 0.37 & -0.30 \\
$\mathrm{NO}_{2}$ & 0.19 & 0.14 & 0.37 & 1 & -0.55 \\
$\mathrm{O}_{3}$ & 0.06 & 0.12 & -0.30 & -0.55 & 1 \\
\hline
\end{tabular}

\section{References}

1. Kukkonen, J.; Konttinen, M.; Bremer, P.; Salmi, T.; Saari, H. The seasonal variation of urban air quality in northern European conditions. Int. J. Environ. Pollut. 2000, 14, 480. [CrossRef]

2. Ma, C.; Ding, L. A research on the seasonal difference of air pollution in Chengdu. IOP Conf. Ser. Earth Environ. Sci. 2020, 569, 012071. [CrossRef]

3. Johansson, C.; Norman, M.; Gidhagen, L. Spatial \& temporal variations of PM10 and particle number concentrations in urban air. Environ. Monit. Assess. 2007, 127, 477-487. [PubMed]

4. Hoek, G.; Brunekreef, B.; Verhoeff, A.; van Wijnen, J.; Fischer, P. Daily mortality and air pollution in The Netherlands. J. Air Waste Manag. Assoc. 2000, 50, 1380-1389. [CrossRef]

5. Peng, R.D.; Dominici, F.; Pastor-Barriuso, R.; Zeger, S.L.; Samet, J.M. Seasonal Analyses of Air Pollution and Mortality in 100 US Cities. Am. J. Epidemiol. 2005, 161, 585-594. [CrossRef]

6. Nawrot, T.S.; Torfs, R.; Fierens, F.; de Henauw, S.; Hoet, P.H.; van Kersschaever, G.; de Backer, G.; Nemery, B. Stronger associations between daily mortality and fine particulate air pollution in summer than in winter: Evidence from a heavily polluted region in western Europe. J. Epidemiol. Community Health 2007, 61, 146-149. [CrossRef]

7. Läll, K.; Raag, M.; Orru, H. Particulate air pollution and mortality in Tallinn: A time-series analysis in North-Eastern European country. Environ. Health Perspect. 2013, 2013, 4177. [CrossRef]

8. Chen, R.; Peng, R.D.; Meng, X.; Zhou, Z.; Chen, B.; Kan, H. Seasonal variation in the acute effect of particulate air pollution on mortality in the China Air Pollution and Health Effects Study (CAPES). Sci. Total Environ. 2013, 450-451, 259-265. [CrossRef]

9. Qian, Z.; Lin, H.M.; Stewart, W.F.; Kong, L.; Xu, F.; Zhou, D.; Zhu, Z.; Liang, S.; Chen, W.; Shah, N.; et al. Seasonal Pattern of the Acute Mortality Effects of Air Pollution. J. Air. Waste. Manag. Assoc. 2010, 60, 481-488. [CrossRef]

10. Yi, O.; Hong, Y.C.; Kim, H. Seasonal effect of PM10 concentrations on mortality and morbidity in Seoul, Korea: A temperaturematched case-crossover analysis. Environ. Res. 2010, 110, 89-95. [CrossRef]

11. Lyon, J.L.; Mori, M.; Gao, R. Is there a causal Association between Excess Mortality and Exposure to PM-10 air Pollution? Additional Analyses by Location, year, Season, and Cause of Death. Inhal. Toxicol. 1995, 7, 603-614. [CrossRef]

12. Hsu, W.H.; Hwang, S.A.; Kinney, P.L.; Lin, S. Seasonal and temperature modifications of the association between fine particulate air pollution and cardiovascular hospitalization in New York State. Sci. Total Environ. 2017, 578, 626-632. [CrossRef]

13. Meister, K.; Johansson, C.; Forsberg, J. Estimated short-term effects of coarse particles on daily mortality in Stockholm, Sweden. Environ. Health Perspect. 2012, 120, 431-436. [CrossRef] [PubMed]

14. Duan, Y.; Liu, X.; Li, H.; Yan, S.; Yan, M.; Mang, Y.; Yin, P. Season and temperature modify the short-term effect of nitrogen dioxide on cardiovascular mortality: A time-series study. Lancet 2019, 394, S57. [CrossRef]

15. Liu, T.; Zeng, W.; Lin, H.; Rutherford, S.; Xiao, J.; Li, X.; Li, Z.; Qian, Z.; Feng, B.; Ma, W. Tempo-Spatial Variations of Ambient Ozone-Mortality Associations in the USA: Results from the NMMAPS Data. Int. J. Environ. Res. Public Health 2016, 13, 851. [CrossRef] [PubMed]

16. Pascal, M.; Wagner, V.; Chatignoux, E.; Falq, G.; Corso, M.; Blanchard, M.; Host, S.; Larrieu, S.; Pascal, L.; Declercq, C. Ozone and short-term mortality in nine French cities: Influence of temperature and season. Atmos. Environ. 2012, 62, 566-572. [CrossRef]

17. Qin, L.; Gu, J.; Liang, S.; Fang, F.; Bai, W.; Liu, X.; Zhao, T.; Walline, J.; Zhang, S.; Cui, Y.; et al. Seasonal association between ambient ozone and mortality in Zhengzhou, China. Int. J. Biometeorol. 2017, 61, 1003-1010. [CrossRef] 
18. Olstrup, H.; Johansson, C.; Forsberg, B.; Åström, C. Association between Mortality and Short-Term Exposure to Particles, Ozone and Nitrogen Dioxide in Stockholm, Sweden. Int. J. Environ. Res. Public Health 2019, 16, 1028. [CrossRef]

19. Auger, N.; Potter, B.J.; Smargiassi, A.; Bilodeau-Bertrand, M.; Paris, C.; Kosatsky, T. Association between quantity and duration of snowfall and risk of myocardial infarction. CMAJ 2017, 189, E235-E242. [CrossRef] [PubMed]

20. Norman, M.; Johansson, C. Studies of some measures to reduce road dust emissions from paved roads in Scandinavia. Atmos. Environ. 2006, 40, 6154-6164. [CrossRef]

21. Khan, R.K.; Strand, M.A. Road dust and its effect on human health: A literature review. Epidemiol. Health 2018, 40, e2018013. [CrossRef] [PubMed]

22. Krecl, P.; Targino, A.C.; Johansson, C. Spatiotemporal distribution of light-absorbing carbon and its relationship to other atmospheric pollutants in Stockholm. Atmos. Chem. Phys. 2011, 11, 11553-11567. [CrossRef]

23. Bedada, G.B.; Raza, A.; Forsberg, B.; Lind, T.; Ljungman, P.; Pershagen, G.; Bellander, T. Short-term exposure to ozone and mortality in subjects with and without previous cardiovascular disease. Epidemiology 2016, 27, 663-669. [CrossRef] [PubMed]

24. Samoli, E.; Aga, E.; Touloumi, G.; Nisiotis, K.; Forsberg, B.; Lefranc, A.; Pekkanen, J.; Wojtyniak, B.; Schindler, C.; Niciu, E.; et al. Short-term effects of nitrogen dioxide on mortality: An analysis within the APHEA project. Eur. Respir. J. 2006, 27, 1129-1138. [CrossRef] [PubMed]

25. Kraft, M.; Eikmann, T.; Kappos, A.; Künzli, N.; Rapp, R.; Schneider, K.; Seitz, H.; Voss, J.U.; Wichmann, H.E. The German view: Effects of nitrogen dioxide on human health-derivation of health-related short-term and long-term values. Int. J. Hyg. Environ. Health 2005, 208, 305-318. [CrossRef]

26. Ritz, B.; Hoffmann, B.; Peters, A. The Effects of Fine Dust, Ozone, and Nitrogen Dioxide on Health. Dtsch. Arztebl. Int. 2019, 116, 881-886. [CrossRef]

27. Meng, X.; Liu, C.; Chen, R.; Sera, F.; Vicedo-Cabrera, A.M.; Milojevic, A.; Guo, Y.; Tong, S.; Coelho, M.D.; Saldiva, P.H.; et al. Short term associations of ambient nitrogen dioxide with daily total, cardiovascular, and respiratory mortality: Multilocation analysis in 398 cities. BMJ. 2021, 372, n534. [CrossRef]

28. Lavigne, E.; Burnett, R.T.; Weichenthal, S. Association of short-term exposure to fine particulate air pollution and mortality: Effect modification by oxidant gases. Sci. Rep. 2018, 8, 16097. [CrossRef]

29. Zhang, Z.; Weichenthal, S.; Kwong, J.C.; Burnett, R.T.; Hatzopoulou, M.; Jerrett, M.; Donkelaar, A.V.; Bai, L.; Martin, R.V.; Copes, R.; et al. Long-term exposure to iron and copper in fine particulate air pollution and their combined impact on reactive oxygen species concentration in lung fluid: A population-based cohort study of cardiovascular disease incidence and mortality in Toronto, Canada. Int. J. Epidemiol. 2021, 50, 589-601. [CrossRef] 